\title{
Building the evidence base for waterpipe regulation and policy
}

\author{
Wasim Maziak, ${ }^{1}$ Eva Sharma (i] ${ }^{2}$
}

${ }^{1}$ Department of Epidemiology, Robert Stempel College of Public Health and Social Work, Florida International University, Miami, Florida, USA

${ }^{2}$ Westat Inc, Rockville, Maryland, USA

\section{Correspondence to} Dr Wasim Maziak, College of Public Health, Florida International University, Miami FL 33174, USA;

wmaziak@fiu.edu

Published Online First 25 November 2019
Check for updates

(c) Author(s) (or their employer(s)) 2020. No commercial re-use. See rights and permissions. Published by BMJ.

To cite: Maziak W, Sharma E. Tob Control

2020:29:559-s61.

\section{ABSTRACT}

Waterpipe (hookah, shisha, narghileh) smoking is emerging as an epidemic, particularly among young people in the USA and globally. Unlike cigarettes, waterpipe smoking involves several components (eg, tobacco, charcoal, device and venues) and is characterised by unique smoking patterns that expose smokers to significant amounts of nicotine and other toxic substances. With the rising prevalence of use among young people and continuing misperceptions about waterpipe's harmful nature, a better understanding of health risks associated with waterpipe smoking is warranted. In response to waterpipe's rising trends, a Deeming Rule that extended the US Food and Drug Administration's (FDA) regulatory authority to all tobacco products was issued in 2016. This rule includes waterpipe tobacco, components and parts. This development created the need for evidence to guide the FDA into best evidence-based strategies to limit waterpipe's spread among young people and harm to public health. This special issue presents some of the studies that were funded under the 'Chemistry, Toxicology, and Addiction Research on Waterpipe Tobacco' programme to inform promising regulatory action on waterpipe products. In this preamble, we briefly summarise findings from these studies and discusses their policy and regulatory implications for different waterpipe products and components.

Tobacco use remains the leading preventable cause of morbidity and mortality worldwide. ${ }^{1}$ Waterpipe tobacco (a.k.a hookah, shisha, narghileh) is an emerging tobacco product that is becoming a global phenomenon. In the USA, waterpipe smoking has become particularly popular among young adults. According to the Population Assessment of Tobacco and Health study, current waterpipe smoking among $18-24$ years olds ranked second $(18.2 \%)$ only to cigarette smoking $(19.6 \%)^{2}$ Studies in specific young adult populations such as college students show a high prevalence of past 12 -month waterpipe use ranging from $22 \%$ to $40 \%$. $^{3}$ The spread of waterpipe smoking among young adults has been driven by the marketing of flavoured tobacco, social media promotion, growth in the number of waterpipe cafés and misperceptions regarding the harmful and addictive nature of waterpipe smoking. ${ }^{3}$ The American Heart Association recently stated that waterpipe smoke delivers known tobacco toxicants and carcinogens and that waterpipe smoking is associated with many of the same risks as cigarettes smoking, such as lung cancer, and respiratory and cardiovascular diseases. ${ }^{4}$ The spread of waterpipe smoking is also perpetuated by the lag in policy and regulatory response to address it. ${ }^{5} 6$ This is not unexpected given its special configuration and characteristics, which influence the applicability of known effective tobacco control policies to this emerging tobacco product.

As commonly used today, the waterpipe consists of a head (where tobacco is placed) a body, a water base and a hose that ends with a mouthpiece. Burning charcoal pieces are placed on top of the tobacco-filled head, separated from the tobacco by a perforated aluminium foil to allow the heated air to pass through the tobacco and generate smoke that passes down a stem and bubbles through the water on its way to the smoker. ${ }^{7}$ A disposable mouthpiece is usually put on the hose's solid mouthtop for individual use. Different waterpipe components (tobacco, device and charcoal) contribute to its harmful profile and need to be accounted for in any policy and regulatory framework addressing it. Moreover, compared with cigarettes the waterpipe is a less standardised product with multiple looselydefined industries behind its marketing. This includes waterpipe lounges/cafés, which represent a unique 'vector' in the waterpipe epidemic that targets youth and college campuses and is propagating waterpipe spread among them. ${ }^{8}$

Under the Family Smoking Prevention and Tobacco Control Act (TCA), 2009, the US Food and Drug Administration (FDA) was authorised to regulate the manufacturing, packaging, labelling, advertising, sales and distribution of tobacco products. ${ }^{9}$ In 2016, the FDA extended its regulatory authority under the TCA to include waterpipe products. Accordingly, the FDA Center for Tobacco Products now regulates waterpipe tobacco, charcoal, parts and accessories. ${ }^{10}$ This important development opened the door to start considering evidencebased approaches to reduce waterpipe smoking in the USA. It also created the need for evidence to guide local and national authorities into effective strategies to limit the public health impact of smoking.

This need for evidence to guide the FDA into effectively regulating waterpipe products was behind the 'Chemistry, Toxicology, and Addiction Research on Waterpipe Tobacco' (R01) funding programme. The programme aims to encourage biomedical, behavioural and social science research that will inform the development and evaluation of possible regulatory action on waterpipe tobacco products. Nine teams funded under this programme collaborated in presenting their findings in this special issue, and this commentary provides a synopsis of these studies and discusses their potential regulatory and policy implications. ${ }^{11-19}$ 


\section{WATERPIPE TOBACCO FLAVORS}

Flavoured waterpipe tobacco is a major attractant to youth and has been suggested as one of the drivers of the waterpipe epidemic among youth (WHO advisory). In 2014, about $80 \%$ of smokers aged 12-17 years old in the USA reported using waterpipe because it comes in flavours they liked. ${ }^{20}$ The FDA recently issued an advance notice of proposed rulemaking to obtain information on the role of flavours in attracting youth to initiate tobacco product use that may result in sustained use through adulthood. ${ }^{21}$ Studies on flavour use among waterpipe users can help the FDA's understanding as the rulemaking process continues.

In this special issue, Ben Taleb et $a l^{11}$ examined the impact of flavoured and non-flavoured waterpipe tobacco on subjective measures of satisfaction, harm perception, withdrawal symptoms and nicotine exposure in a sample of waterpipe smokers. Smoking the flavoured waterpipe tobacco was associated with enhanced subjective experiences compared with the nonflavoured, suggesting a potential role for flavour regulation in reducing waterpipe use. Mixed results were observed for toxicants exposure in relation to smoking flavoured compared with non-flavoured products suggesting the need for a more comprehensive assessment of the effects of other tobacco constituents and additives on toxicant exposure in waterpipe smokers. Using the same dataset, Maziak and colleagues ${ }^{12}$ examined the differences in waterpipe smokers' responses to changes in flavour according to waterpipe use frequency (high-frequency vs lowfrequency use), and showed that high-frequcney smokers were more sensitive to flavour manipulation compared with low frequency. Combined, these studies indicate that limiting flavour will likely reduce waterpipe satisfaction and future use and that such an effect will be more pronounced among 'more established' frequent waterpipe smokers.

Stroud et $a l^{13}$ investigated use, preferences and perceptions of waterpipe tobacco flavours in a racially/ethnically diverse sample of pregnant waterpipe users, and their impact on waterpipe use during preconception and first trimester of pregnancy. Pregnant waterpipe users reported nearly exclusive use of flavoured tobacco, and reported the greatest use of mint/menthol and fruit flavours compared with other flavours. Compared with dual/poly tobacco waterpipe users, exclusive waterpipe users reported stronger preferences for mint/menthol flavoured waterpipe tobacco. Preference for mint/menthol and fruit flavours predicted increased waterpipe tobacco use episodes during preconception and first trimester of pregnancy. Such results suggest that limiting flavours may curb the appeal and use of waterpipe tobacco among pregnant women.

\section{WATERPIPE DESIGN FEATURES, COMPONENTS AND SMOKING TOPOGRAPHY}

Understanding the effects of waterpipe design and components on waterpipe tobacco mainstream smoke is crucial for regulatory action aimed at minimising waterpipe-associated harmful exposures. As charcoal used in waterpipe smoking is the main source of major toxicants such as carbon monoxide (CO) and polycyclic aromatic hydrocarbons, investigating the effects of alternative heating sources with the potential to reduce such emissions can be helpful to guide waterpipe regulations. Using machine smoking, Brinkman and colleagues ${ }^{14}$ investigated the effects of two different tobacco heating methods, quick-light charcoal and electric heater, and two water bowl preparations, with and without ice, on mainstream total particulate matter (TPM), nicotine, menthol, semi-volatile furan and $\mathrm{CO}$ yields. Electric heating resulted in 2.4 times more tobacco consumption, 1.4 times higher mainstream nicotine and semi-volatile furan yields, and lower mainstream $\mathrm{CO}$ and pyrene yields compared with charcoal heating. Adding ice to the bowl resulted in decreased TPM for charcoal heating, and higher furan yields for electric heating, demonstrating that waterpipe components can affect mainstream toxicant yields. Overall, mainstream semi-volatile furan yields were 85-2500 times higher than those reported for cigarettes. These chemicals are likely the thermal degradation products of added sugars. Waterpipe tobacco is more heavily fortified with simple sugars, 15-50 times more than any other combustible tobacco product. The sparse literature on the toxicology of acute and chronic inhalation of semi-volatile furans, which have carcinogenic and mutagenic potential, represents a significant data gap and barrier to effective tobacco control for waterpipe. In another study, Hauser and colleagues ${ }^{15}$ studied the effects of waterpipe size on the physical properties and cytotoxicity of the smoke produced. They showed that as waterpipe height and bowl size decreased, mean particle size decreased and total particle concentration and waterpipe smoke toxicity increased. Exposing alveolar cells to smoke generated from all waterpipe sizes tested caused cell death but smoke from smaller waterpipes, such as those currently marketed to individual users, resulted in significantly more cell death. Eddingsaas et $a l^{16}$ studied the effect of waterpipe puff topography (eg, puff duration and flow rate) on the quantity and characteristics of mainstream emissions from waterpipe including TPM, the mass ratio of nicotine to TPM and amount of volatile carbonyls. Results showed that for particulate matter the dominant topography factor was puff flow rate, while for individual volatile carbonyl compounds, the emissions were affected by puff duration with the concentration of formaldehyde increasing while others decreased at longer puff duration. Together, these studies show that waterpipe components, size and puffing patterns all influence waterpipe toxicant yields and provide important regulatory insights and targets to reduce such emissions and their associated harm to smokers and those surrounding them.

Kassem and colleagues ${ }^{17}$ quantified post-smoking waterpipe tobacco waste, device cleaning practices and disposal of waterpipe tobacco smoking associated waste in homes of waterpipe smokers. About two-thirds of the waterpipe tobacco used during one smoking session and most of the water used in the waterpipe bowl were discarded as waste. Waterpipe device cleaning practices ranged from never cleaning to cleaning it after each use. Locations of disposal of waste post smoking included the trash, kitchen sink, bathroom sink, toilet, shower beds, indoor plant pots, backyard soil and street storm drains. This study shows that waterpipe-associated toxic waste discarded in home settings may linger in indoor and outdoor environments with the potential of ending up in landfills and water resources, necessitating the need for policies and advocacy work to reduce the environmental impact of waterpipe tobacco smoking waste.

\section{HEALTH EFFECTS OF SMOKING WATERPIPE}

Unlike other combustible tobacco products, waterpipe users often underestimate the health risks associated with waterpipe smoking. With the rising prevalence of waterpipe use and continuing misperceptions about waterpipe harm, a better understanding of health risks associated with waterpipe smoking is warranted. Reyes-Caballero et $a l^{18}$ studied the effects of waterpipe smoke on the lungs immune system and function in a murine model. Waterpipe smoke was generated for three waterpipe puffing regimens, where mice were chronically exposed for 
6 months to each of the regimens. The lung immune response showed a dose-dependent decrease in airway inflammatory cells and chemokines in the waterpipe smoke-exposed animals compared with air-exposed controls. Acute waterpipe exposure identified known and novel immediate-early genes with potential as biomarkers of waterpipe exposure. This research on chronic exposure to waterpipe and the discovery of immediate-early genes after acute exposure addresses the need for developing genetic biomarkers that are specifically tailored to waterpipe use.

Finally, Khan NA et $a l^{19}$ studied biomarkers of oxidative stress and inflammation in a sample of waterpipe, conventional cigarette and dual users of waterpipe and cigarettes. Plasma levels of oxidative stress and inflammatory biomarkers were significantly elevated in all the smoking groups compared with non-smoking controls. Cigarette and waterpipe smokers had comparable levels of various inflammatory and lipid mediators, however, the levels were higher in dual smokers compared with either waterpipe or cigarette smokers alone. The results suggest that dual use of waterpipe and cigarettes can be more harmful than smoking cigarettes or waterpipe tobacco alone.

\section{CONCLUSIONS}

These studies show how waterpipe components (tobacco, device and charcoal) and constituents (eg, flavour) influence smokers' experience, smoking patterns and toxicity of waterpipe smoke. The studies also increase our understanding of the effects of different topography parameters such as puffing patterns and duration of exposure on smoke characteristics and constituents, as well as their potential effect on different organs and systems. This supplement provides a first step toward approaching waterpipe policy and regulation in an evidence-based manner that reflects waterpipe's unique characteristics and configuration. It also identifies targets for regulation, such as limiting flavours and increasing awareness about harms associated with waterpipe smoking. These strategies have the potential to reduce waterpipe use, including among vulnerable populations such as youth and pregnant women. Finally, the studies call for sustained investment to build the evidence base needed to effectively address the waterpipe threat to public health in the USA.

Contributors Both authors made substantial contributions to the commentary.

Funding This supplement and the authors' effort on this project were supported by the Center for Evaluation and Coordination of Training and Research in Tobacco Regulatory Science award (5U54CA189222) from the National Cancer Institute and the US Food and Drug Administration. The grants that support the research presented in this issue are cited in the individual articles.

Disclaimer The content of this paper is solely the responsibility of the authors and does not necessarily represent the official views of Westat, the National Institutes of Health, or the US Food and Drug Administration.

Competing interests None declared.

Patient consent for publication Not required.

Provenance and peer review Not commissioned; internally peer reviewed.
ORCID iD

Eva Sharma http://orcid.org/0000-0002-1328-508X

\section{REFERENCES}

1 U.S. Department of Health and Human Services. The health consequences of Smoking - 50 years of progress: a report of the Surgeon General. Atlanta GA: U.S. Department of Health and Human Services, Centers for Disease Control and Prevention, National Center for Chronic Disease Prevention and Health Promotion, Office on Smoking and Health, 2014.

2 Kasza KA, Ambrose BK, Conway KP, et al. Tobacco-product use by adults and youths in the United States in 2013 and 2014. N Engl J Med 2017;376:342-53.

3 Maziak W, Taleb ZB, Bahelah R, et al. The global epidemiology of waterpipe smoking. Tob Control 2015;24:i3-12.

4 Bhatnagar A, Maziak W, Eissenberg T, et al. Water pipe (Hookah) smoking and cardiovascular disease risk: a scientific statement from the American Heart Association. Circulation 2019;139.

5 Haddad L, El-Shahawy O, Ghadban R, et al. Waterpipe smoking and regulation in the United States: a comprehensive review of the literature. Int J Environ Res Public Health 2015:12:6115-35.

6 Colditz JB, Ton JN, James AE, et al. Toward effective water pipe tobacco control policy in the United States: synthesis of federal, state, and local policy Texts. Am J Health Promot 2017:31:302-9.

7 Maziak Wet al. Tobacco smoking using a waterpipe: a re-emerging strain in a global epidemic. Tob Control 2004;13:327-33.

8 Kates FR, Salloum RG, Thrasher JF, et al. Geographic proximity of waterpipe smoking establishments to colleges in the U.S. Am J Prev Med 2016;50:e9-14.

9 U.S. Food and Drug Administration. Family smoking prevention and tobacco control act. public law 111-31, 2009. Available: https://www.fda.gov/tobaccoproducts/guid ancecomplianceregulatoryinformation/ucm261829.htm [Accessed 10 Apr 2019].

10 US Department of Health and Human Services, Food and Drug Administration. Deeming tobacco products to be subject to the federal food, drug, and cosmetic act, as amended by the family smoking prevention and tobacco control act (2016. 21 cfr parts 1100, 1140, and 1143. Available: http://www.fda.gov/TobaccoProducts/ Labeling/RulesRegulationsGuidance/ucm394909.htm [Accessed 10 Apr 2019].

11 Ben Taleb Z, Vargas M, Ebrahimi Kalan M, et al. The effect of flavoured and nonflavoured tobacco on subjective experience, topography and toxicant exposure among waterpipe smokers. Tobacco Control 2020;29:s72-9.

12 Maziak W, Ben Taleb Z, Ebrahimi Kalan M, et al. Effect of flavour manipulation on low and high-frequency waterpipe users' puff topography, toxicant exposures and subjective experiences. Tobacco Control 2020;29:s95-101.

13 Stroud L, Werner E, Matteson K, et al. Waterpipe (hookah) tobacco use in pregnancy: use, preferences and perceptions of flavours. Tob Control 2020;29(Supp 2):s69-71.

14 Brinkman MC, Teferra AA, Kassem NO, et al. Effect of electric heating and ice added to the bowl on mainstream waterpipe semivolatile furan and other toxicant yields. Tob Control 2020;29(Supp 2):s110-6.

15 Hauser $C D$, Mailig R, Stadtler $\mathrm{H}$, et al. Waterpipe tobacco smoke toxicity: the impact of waterpipe size. Tob Control 2020;29(Supp 2):s90-4.

16 Eddingsaas NC, Hensel EC, O'Dea S, et al. Effect of user puffing topography on total particulate matter, nicotine and volatile carbonyl emissions from narghile waterpipes. Tob Control 2020;29(Supp 2):s117-22.

17 Kassem NOF, Kassem NO, Liles S, et al. Waterpipe device cleaning practices and disposal of waste associated with waterpipe tobacco smoking in homes in the USA. Tob Control 2020;29(Supp 2):s123-30.

18 Reyes-Caballero H, Park B, Loube J, et al. Immune modulation by chronic exposure to waterpipe smoke and immediate-early gene regulation in murine lungs. Tobacco Control 2020;29(Supp 2):s80-9.

19 Khan NA, Lawyer G, McDonough S, et al. Systemic biomarkers of inflammation, oxidative stress and tissue injury and repair among waterpipe, cigarette and dual tobacco smokers. Tob Control 2020;29(Supp 2):s102-9.

20 Ambrose BK, Day HR, Rostron B, et al. Flavored tobacco product use among US youth aged 12-17 years, 2013-2014. JAMA 2015;314:1871-3.

21 US. Food and Drug Administration. Advance notice of proposed rulemaking, 2018 Available: https://www.federalregister.gov/documents/2018/03/21/2018-05655/ regulation-of-flavors-in-tobacco-products [Accessed 10 Apr 2019]. 